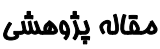

\section{بررسى فراوانى هاييرلييدمى و برخى عوامل موثر بر آن در معلمان استان خراسان شمالى}

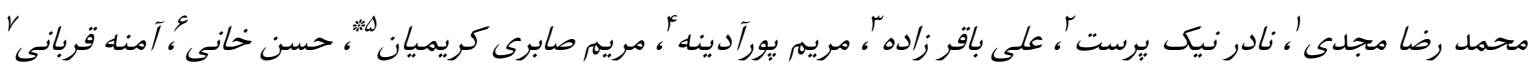
'متخصص بيمارى هاى كودكان و نوزادان، عضو هيات علمى دانشخاه علوم يزشكى مشهر، ايران

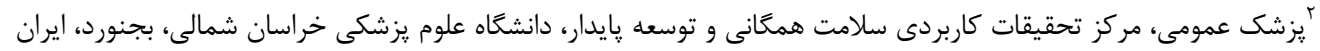

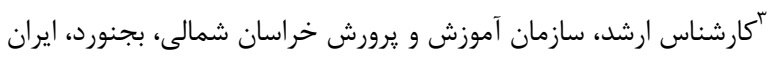

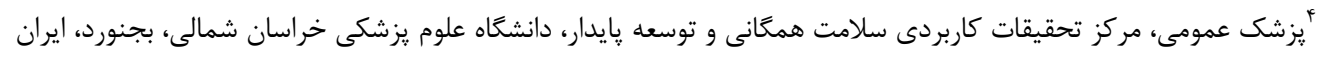

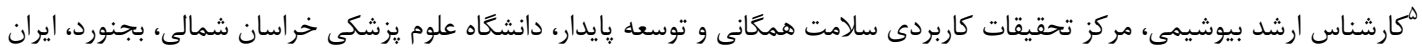

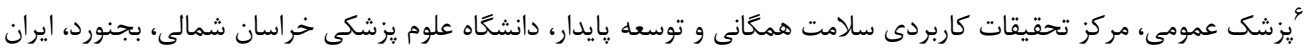

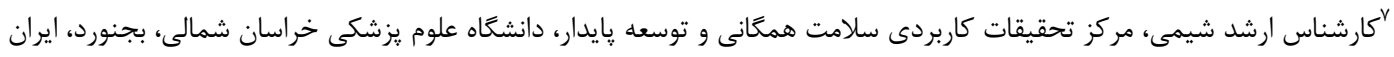

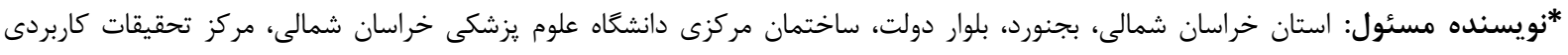

سلامت همخانى و توسعه هِايدار maryam_sabery2005@yahoo.com : يست الكترونيك وسابن

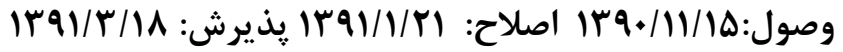

جكيده

زمينه و هدف: ليبيدها در بسيارى /ز اعمال حياتى بلد، نقش مهمر/يفا مى كنند، /ما افزايش آنها مى تواند خطر بيمارى قلبى - عروقى را

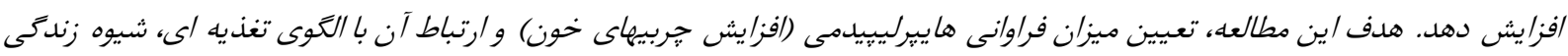
و شاخصهاى آنترويومتريك (تن سنجى) مي مئ باشد.

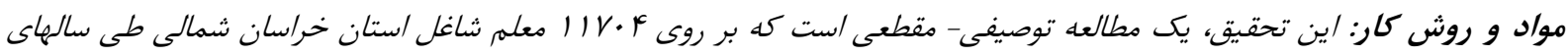

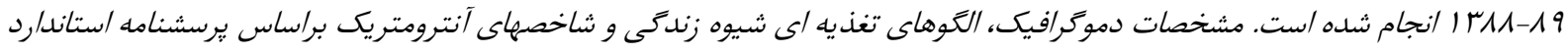

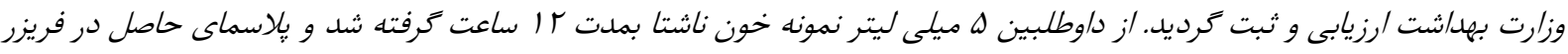

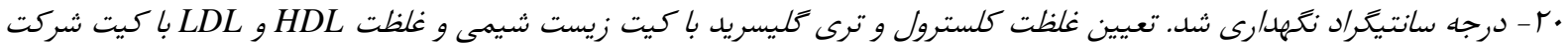

$$
\text { بيوسيسته /نجام شد. }
$$

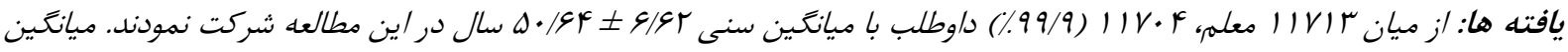

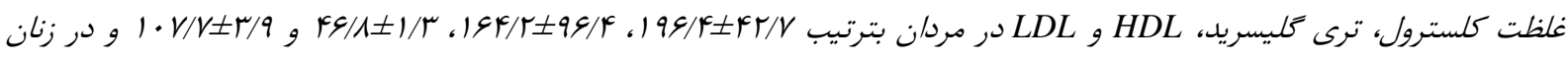
LDL

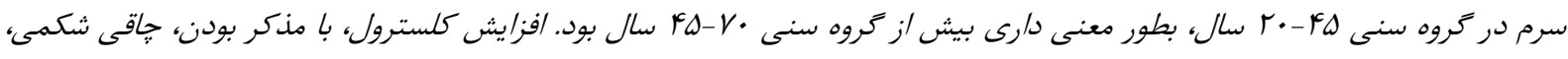

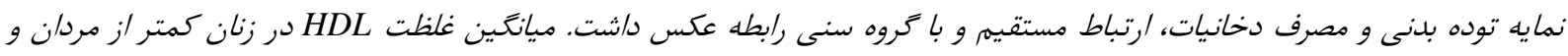

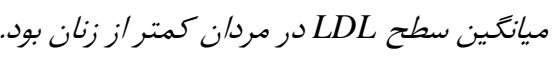

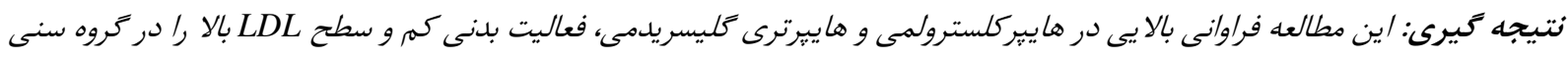

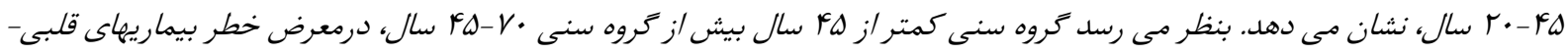
عروقى قرار دارند. وازه هاى كليدى : هاييرليييدمى، بيمارى قلبى -عروقى، معلمان 


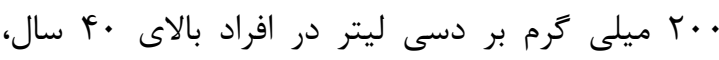

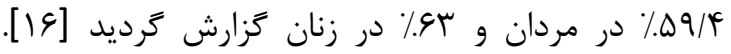
مطالعات نشان داده اند بيشترين نسبت كلسترول در دران

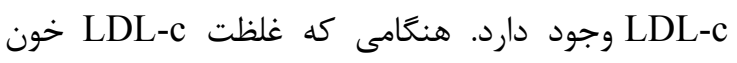
افزايش مى يابد، به آرامى در جدار داخلى شريان هاى

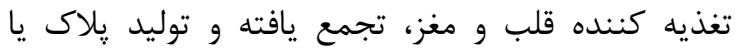

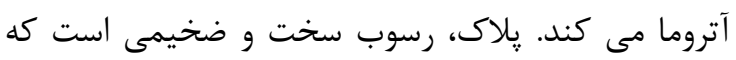
موجب باريك و تنگ شدن شريان ها و كاهش آنس انعطاف

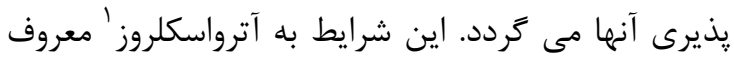
است كه ممكن است منجر به حمله قلبى يا يا سكته ائه

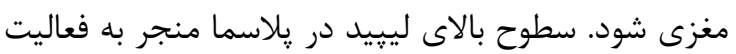

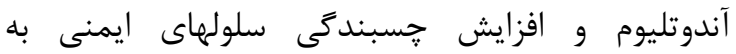

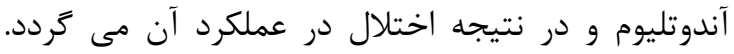

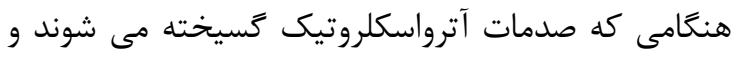
فاكتورهاى كموتاكتيك آزاد مى شوند، تجمع عِلاكتهها،

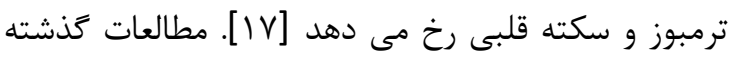

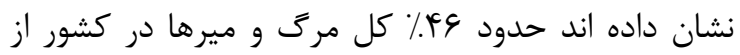

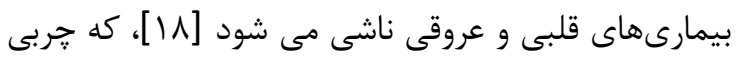
خون يكى از مهمترين عوامل خطر آن مى باشد. با توجه

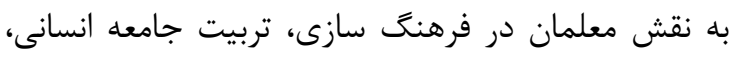

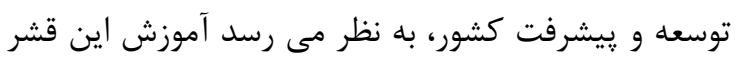
مى تواند نقش مهمم و موثرى در آموزش ساير اقشار جامعه

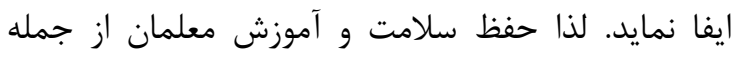

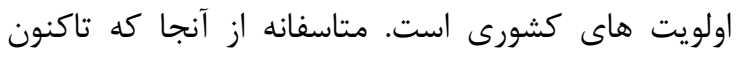
مطالعه اى در استان خراسان شمالى بر روى معلمان انجام

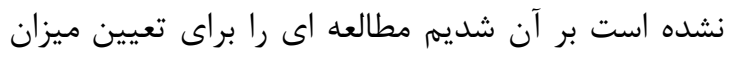

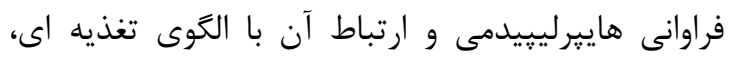

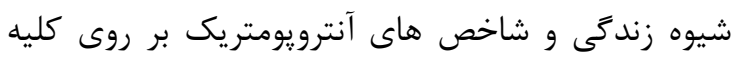
معلمان شاغل در استان خراسان شمالى انجام دهيم تالى

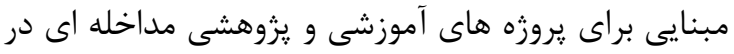
جامعه در جهت بهبود وضعيت سلامت جامعه، بيشكَيرى و كاهش خطر بيمارى هاى قلبى و عروقى را فر اهم نمائيم.

\section{روش كار}

اين تحقيق يك مطالعه توصيفى- مقطعى است كه در IIV.F اداره كل آموزش و يروش استان خراسان شمالى و دانشكاه

1 -Atherosclerosis
مقدمه

جربى ها در بسيارى از اعمال حياتى بدن، نقش مهامه و اساسى را ايفا مى نمايند كه از آن جمله مى توان به حفظ آنس

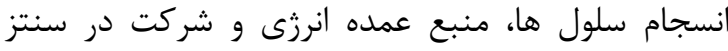
هورمون هاى استروئيدى و بسيارى اعمال ديخر اشاره نمود [1]. افزايش خربيهاى خون يا همان هاييرليييدمى،

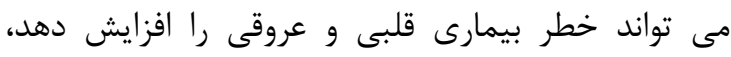

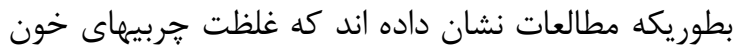
با عوامل متعددى از قبيل الكوى زندگىى، رزيم غذايى،

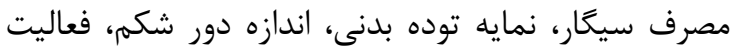

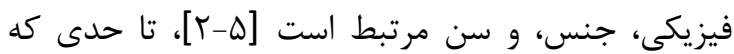
تغيير رزيم غذايى و افزايش فعاليت فيزيكى، مى تواند سطح جربى خون را كاهش دهد [ع]. در كشور آمريكا، حدود نيمى از افراد بالغ داراى مقادير كلسترول بالاتر از

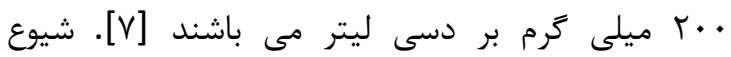

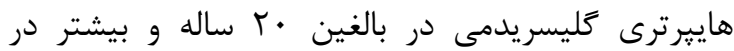

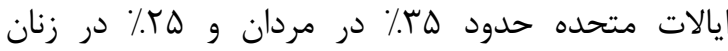

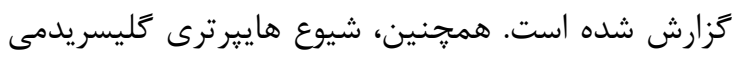

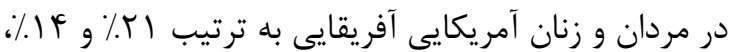

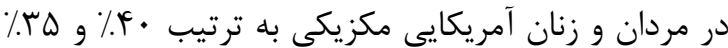

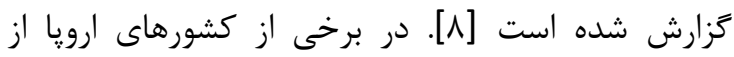

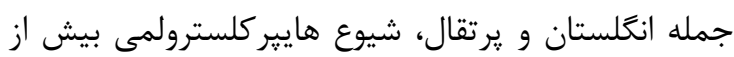

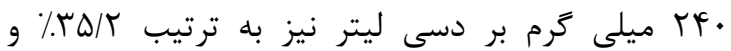

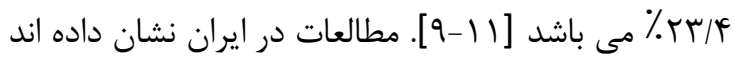

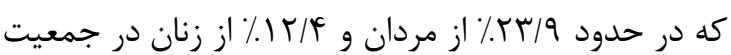
عمومى داراى هايير كلسترولمى مى باشند [1 [1]. بطوريكه

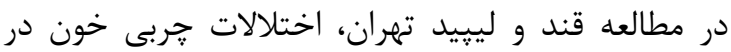

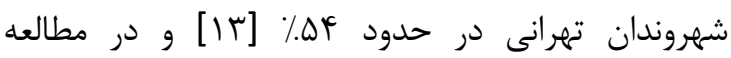
اصفهان فراوانى افزايش كلسترول خون سب در درصد و

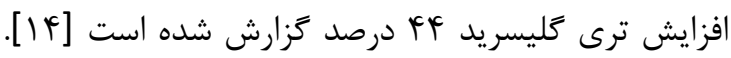

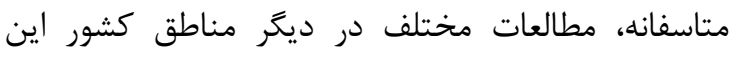

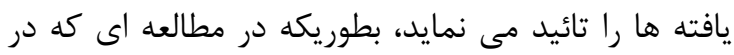

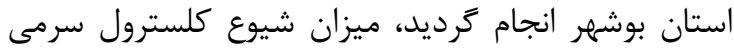

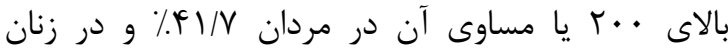

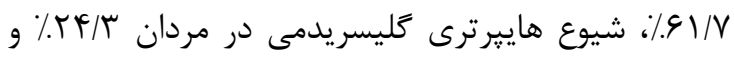

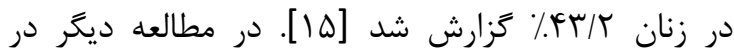
مشهد نيز، شيوع افزايش سطح كلسترول خون بيش از 
بر اساس متغيرات وزن و قد ارزيابى و به جهار گروه لاغر (N/D) ش

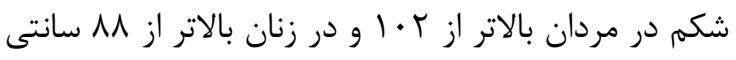

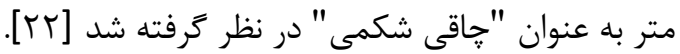

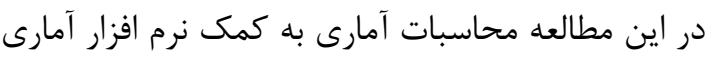
SPSS 16.0 استفاده از تست هاى آمارى تى مستقل و و كاى دون دو انجام كرديد. ميزان P كمتر از هـ/• در اين مطالعه معنى دار

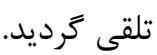

يافته ها

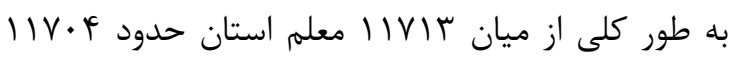

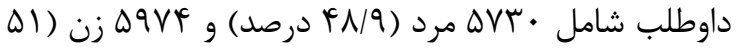

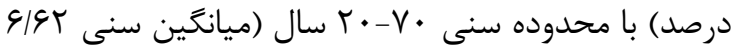
أن

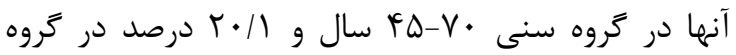

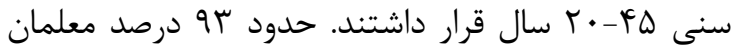

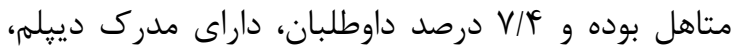

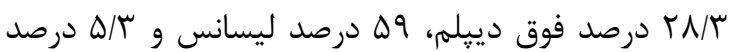
فوق ليسانس بوده اند. ميانكين غلظت كلسترول، ترى كليسريد، HDL

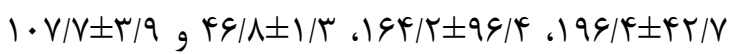
و در زنان 19/1/9

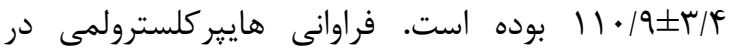

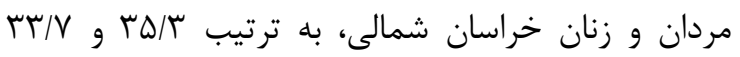

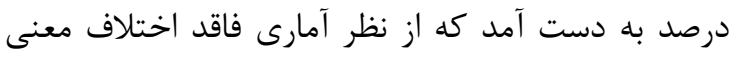

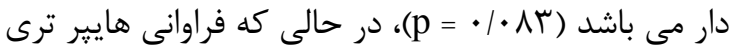

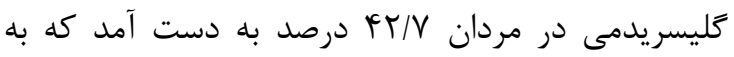

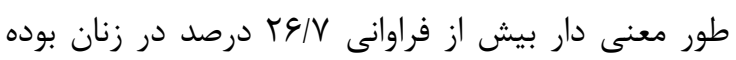

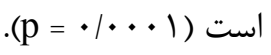

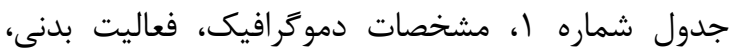
شاخص هاى آنترويومتريك و مصرف دخانيات جمعيت

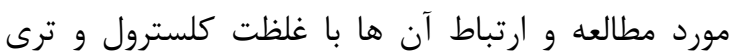
كليسريد سرم را نشان مى دهد. ميانكَين غلظت كلسترول

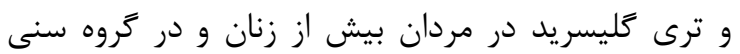

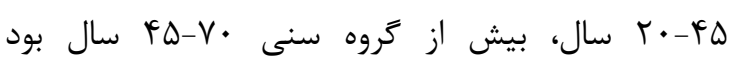

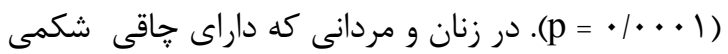

علوم يزشكى و خدمات بهداشتى درمانى انجام شده است. كليه ملاحظات اخلاقى در طى تمامى مراحل مطالعه رعايت كرديد، به طورى كه در ابتدا اهداف اين مطالعه به داهيه

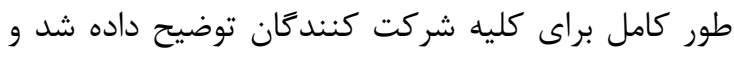
سيس از افراد رضايت نامه كتبى كرفته شد. كليه اطلاعاتى كه از داوطلبان كرفته شد و نيز نام آنان محرمانه باقى خواهد ماند و نتايج تحقيقات به صورت كلى و و در قالب دان اطلاعات گروه مورد مطالعه، منتشر خواهد شد. همجنين مشاركت در اين يزوهش كاملا" اختيارى بوده است.

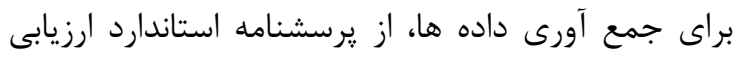

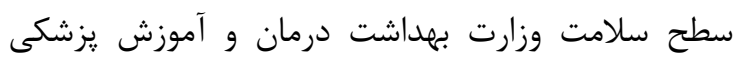
استفاده كرديد. مشخصات دموكرافيك شامل سن، جنس،

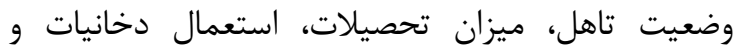

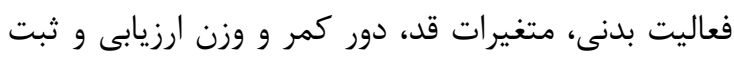

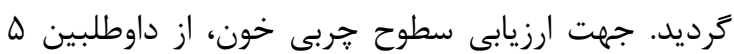

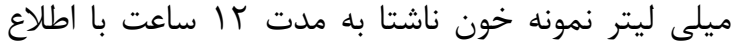

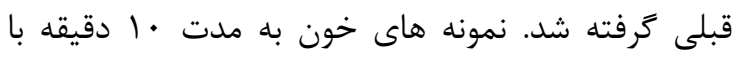

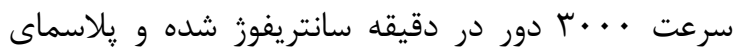

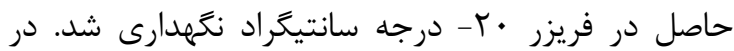

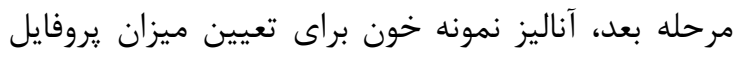

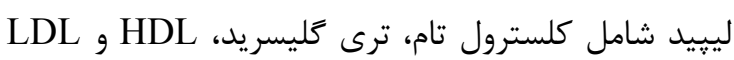
در جمعيت مورد مطالعه انجام شد. به منظور تعيين سطح جربى هاى خون از روش هاى آنزيمى روتين و دستخاه اتوآنالايزر (Parsazmun kit, Karaj, Iran) Cobas auto-analyser system, ABX ) (Diagnostics, Montpellier, France

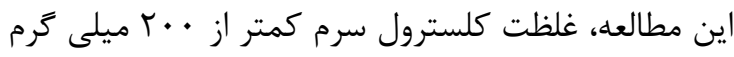

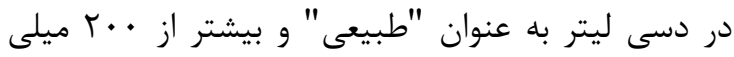

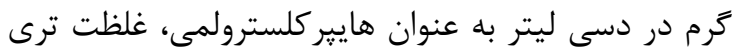

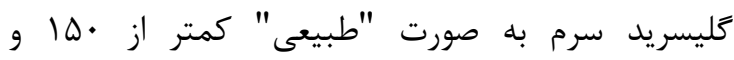

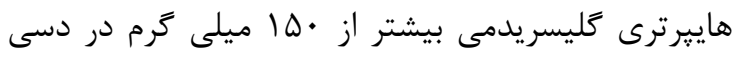

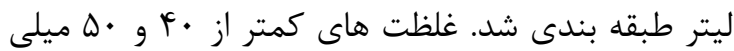
كرم در دسى ليتر كلسترول HDL به ترتيب در مردان و

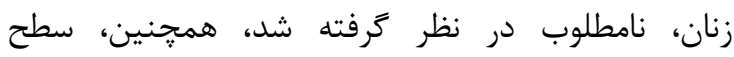

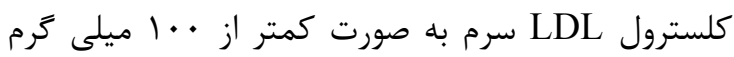

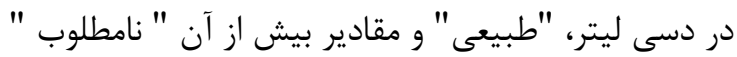

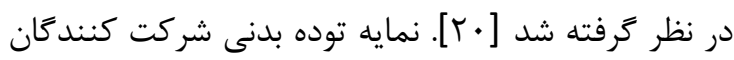




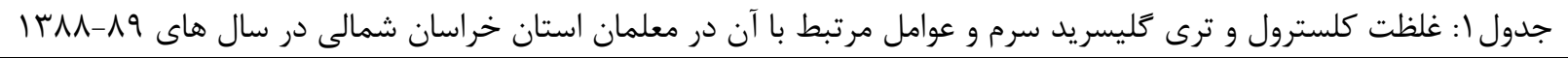

\begin{tabular}{|c|c|c|c|c|c|c|}
\hline \multicolumn{2}{|c|}{ ترى كليسريد سرم } & \multicolumn{2}{|c|}{ كلسترول سرم } & \multirow{2}{*}{$\begin{array}{c}\text { فراوانى } \\
\text { (\%) }\end{array}$} & \multirow[b]{2}{*}{ 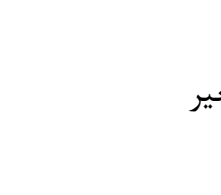 } & \multirow[b]{2}{*}{ مت مت } \\
\hline $\begin{array}{c}\text { P-Value } \\
\text { (ANOVA) }\end{array}$ & ميانگين (انحراف معيار) & $\begin{array}{l}\text { P-Value } \\
\text { (ANOVA) }\end{array}$ & 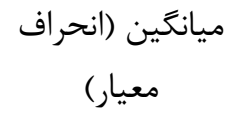 & & & \\
\hline \multirow{2}{*}{$\cdot 1 \cdot \cdots 1$} & $\mid \& Y / T \pm q \& / \mathcal{F}$ & \multirow{2}{*}{$\cdot 1 \cdots \cdot 1$} & $19 G / F \pm F r / V$ & $\Delta 1 / 1$ & مرد & \multirow{2}{*}{ جنس } \\
\hline & $|r r /| \pm V \mid$ & & $19 \cdot / 9 \pm r q / 1$ & FN/q & زن ان & \\
\hline \multirow{2}{*}{$\cdot 1 \cdot \cdots 1$} & $\mid \xi \% / F \pm 99 / r$ & \multirow{2}{*}{$\cdot \cdots \cdot 1$} & $r \cdot \varepsilon / \Delta \pm r \Delta / r$ & $r \cdot / 1$ & $r \cdot-r \Delta$ & \multirow{2}{*}{ عَروه سنى } \\
\hline & $|F r / q \pm \Lambda| / V$ & & $19 \cdot / r \pm r q / \Delta$ & $\vee q / q$ & $f \Delta-V$. & \\
\hline \multirow{6}{*}{$\cdot 1 \cdot \cdot 1$} & $\mid \psi \wedge \pm \wedge \varepsilon / \tau$ & \multirow{6}{*}{$\cdot \cdots \cdot 1$} & $\mid q r / \Lambda \pm F / / 1$ & $\Lambda \Delta / \Lambda$ & عدم فعاليت & \multirow{6}{*}{ انجام ·r دقيقه } \\
\hline & $|r V /| \pm \varphi q$ & & $\mid \Lambda N / r \pm r G / r$ & $r / 1$ & يك بار & \\
\hline & $|\varepsilon| / \Delta \pm 1 \cdot r / 4$ & & $|q V /| \pm F F / D$ & $1 / r$ & دو بار & \\
\hline & $|Q V / T \pm \wedge \varepsilon /|$ & & $198 / r \pm r r$ & $r / 9$ & سه بار & \\
\hline & $\mid r V / \Lambda \pm \varepsilon r / D$ & & $198 / 0 \pm r q / r$ & .19 & جهار بار & \\
\hline & $\mid r r \pm \wedge r / \varphi$ & & $\mid \Lambda V / F \pm F r / q$ & $9 / 9$ & كل هفته & \\
\hline \multirow{2}{*}{$\cdot 1 \cdot \cdots 1$} & $119 / \Delta \pm \Delta V / 9$ & \multirow{2}{*}{$\cdot 1 \cdot \cdot \cdot 1$} & $1 \wedge 9 / r \pm r q / \Delta$ & $G T / r$ & طبيعى & \multirow{4}{*}{ جاقى شكمى } \\
\hline & $1 \Delta r / q+\Lambda F / F$ & & $199 / \Delta \pm r r$ & $r V / V$ & بالال & \\
\hline \multirow{2}{*}{$\cdot 1 \cdot \cdots 1$} & $\mid \Delta 9 / 1 \pm 91 / \Delta$ & \multirow{2}{*}{$\cdot 1 \cdots 1$} & $19 r / 4 \pm r \cdot / 9$ & $91 / 1$ & طبيعى & \\
\hline & $r \mid V / r \pm I r \Delta / V$ & & $r \cdot r / \Delta \pm r V / r$ & $1 / 9$ & بالا & \\
\hline \multirow{4}{*}{$.1 \cdot \cdot 1$} & $1 \cdot r / \mathcal{F} \pm r \varepsilon / V$ & \multirow{4}{*}{$\cdot 1 \cdot \cdot \cdot 1$} & $|V \cdot /| r \pm r \Delta / \Delta$ & $1 / 9$ & لاغر & \multirow{4}{*}{ نمايه توده بدنى } \\
\hline & $\mid r r \pm G F / r$ & & $\mid \Lambda r / \cdot r \pm r \Lambda / q$ & 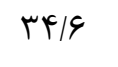 & طبيعى & \\
\hline & $\mid \Delta q / \Lambda \pm \wedge q / V$ & & $19 V / 11 \pm r \cdot 19$ & $Y \wedge / \Lambda$ & افزايش وزن & \\
\hline & $\mid V \Delta / r \pm 99 / \wedge$ & & $r \cdot r / q) \pm r r / F$ & $14 / V$ & جاق & \\
\hline \multirow{2}{*}{$\cdot 1 \cdot \cdots 1$} & $1 \varepsilon \Lambda / 4 \pm 1 \cdot \Lambda / r$ & \multirow{2}{*}{$\cdot 1 \cdot 49$} & $199 / D \pm F r / G$ & $1 / 1$ & بلى بلى & \multirow{2}{*}{ مصرف دخانيات } \\
\hline & $\| \mathcal{F} / \mathcal{F} \pm \wedge \Delta / \mathcal{F}$ & & $|q r / r \pm r| / r$ & $91 / 4$ & خير & \\
\hline
\end{tabular}

درصد، حداقل r روز در هفته ·r دقيقه ورزش با فعاليت بدنى انجام داده اند. جدول شماره ؟، ارتباط جنس، سن واده اند ساير عوامل مرتبط

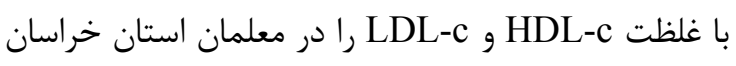
شمالى نشان مى دهد. طبق نتايج حاصل از ماز مطالعه،

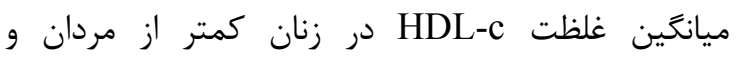
ميانكين سطح LDL-c در مردان كمتر از زنان بوده است

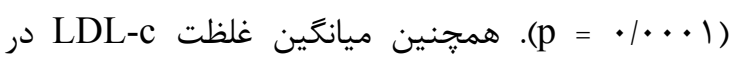

بودند غلظت كلسترول و ترى كليسريد سرم، بيش از افراد

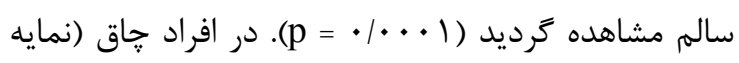
توده بدنى بيش از •ب كيلوَّرم بر متر مربع)، ميانگين

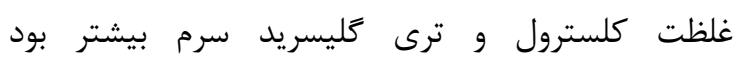

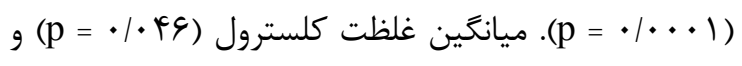

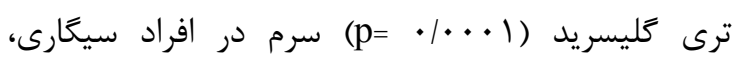

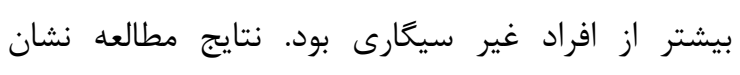

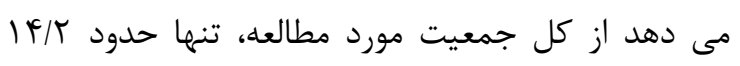


جدول r: غلظت LDL-c و سرم و عوامل مرتبط با آن در معلمان استان خراسان شمالى در سال هاى

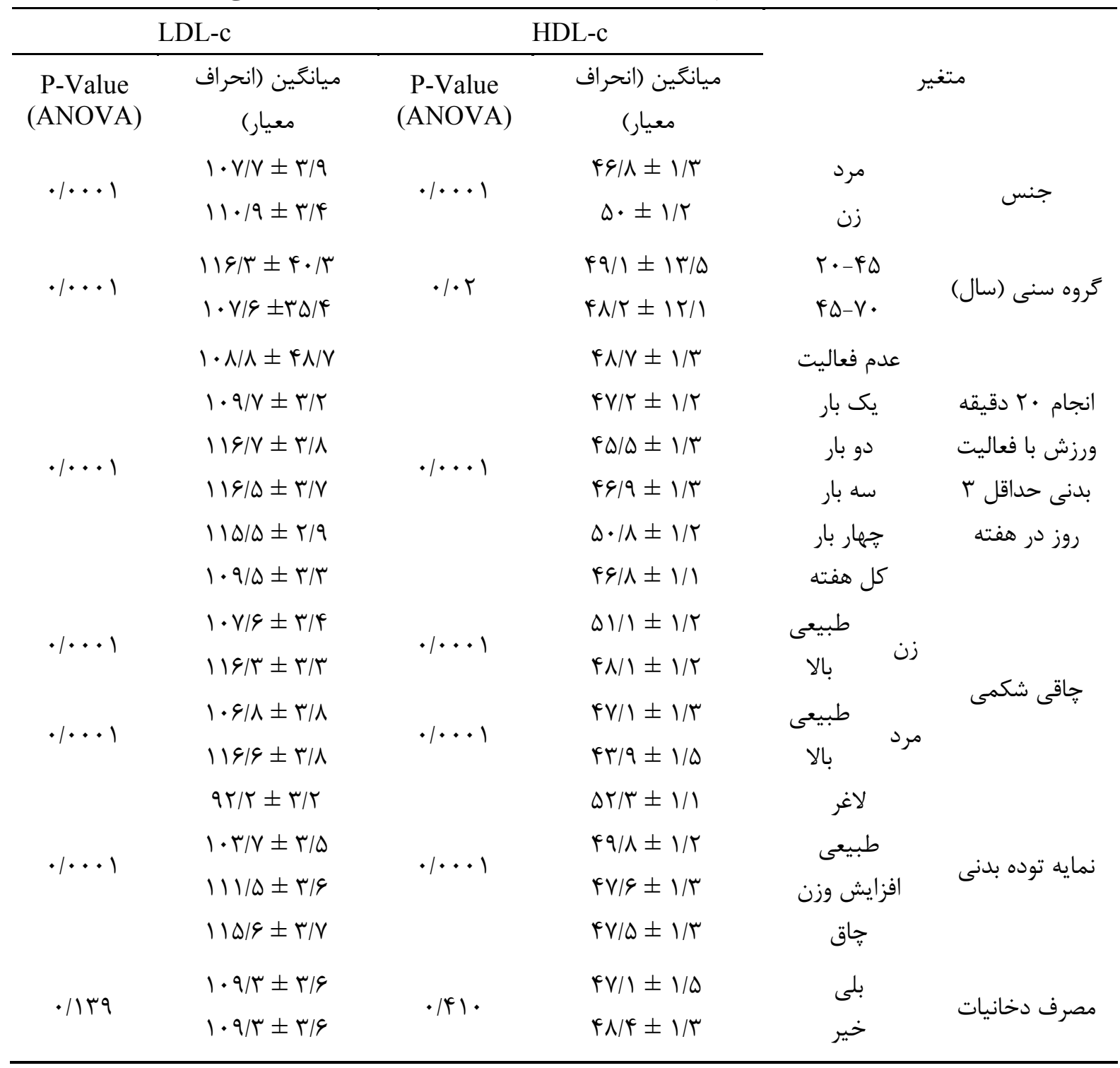

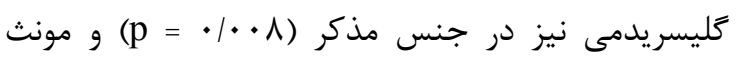

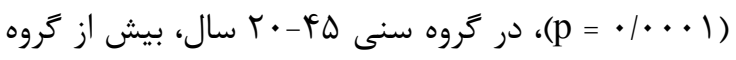
سنى • •l

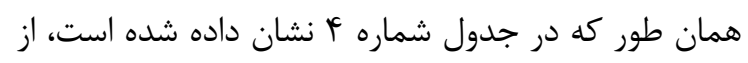

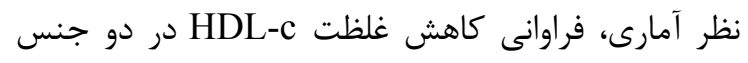
در ₹روه هاى سنى، اختلاف معنى دارى نداشته اند، در حالى كه فراوانى افزايش سطح LDL-c سرم درو در كروه

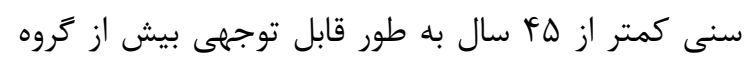

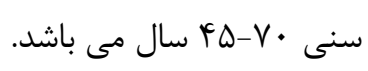

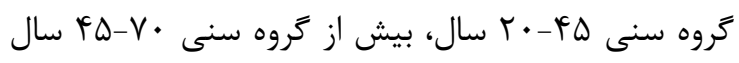

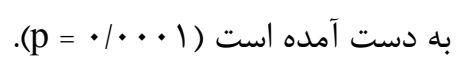
فراوانى هايير كلسترولمى در مردان و زنان به ترتيب سامه

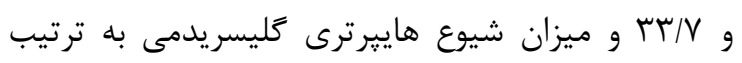

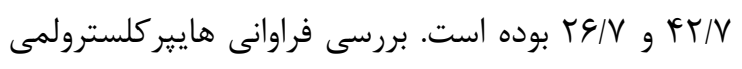
در گروه هاى جنسى در جدول شماره ب، نشان مى دهد

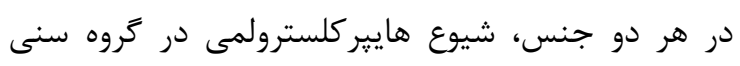

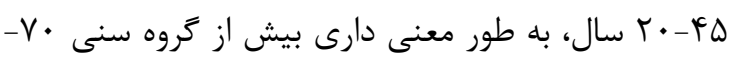

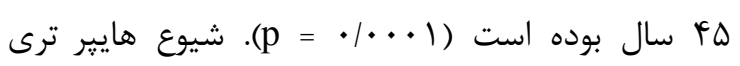


جدول זّ: فراوانى هايير كلسترولمى و هايير ترى كليسريدمى در گروه هاى جنسى بر حسب سن در معلمان استان خراسان شمالى

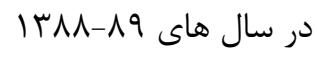

\begin{tabular}{|c|c|c|c|c|c|c|}
\hline $\begin{array}{l}\text { P-Value } \\
(\text { Chi-2) }\end{array}$ & هايير ترى كليسريدمى & $\begin{array}{l}\text { P-Value } \\
\text { (Chi-2) }\end{array}$ & $\begin{array}{c}\text { هايير كلسترولمى } \\
\text { (.) }\end{array}$ & تعداد & گروه سنى (سال) & جنس \\
\hline \multirow{2}{*}{$\cdot / \cdot \wedge$} & $F \Delta / \Lambda$ & \multirow{2}{*}{$\cdot 1 \cdot \cdots 1$} & $p r / q$ & ITYV & كمتر از ه\& سال & \multirow{3}{*}{ مذكر } \\
\hline & fi/V & & Tr/V & Fq.r & بيشتر از هأ سال & \\
\hline- & FT/V & - & $r \Delta / r$ & $\Delta V r$. & كل & \\
\hline \multirow{2}{*}{$\cdot 1 \cdot \cdot 1$} & $r V / l$ & \multirow{2}{*}{$\cdot 1 \cdot \cdot 1$} & $4 q / V$ & I. TD & كمتر از هأ سال & \multirow{3}{*}{ مونث } \\
\hline & $T F / G$ & & $r \cdot 1 \Delta$ & 1901 & بيشتر از هاf سال & \\
\hline- & $r \& / V$ & - & 棌 & $\Delta 9 \wedge \mu$ & كل & \\
\hline
\end{tabular}

جدول fا:فراوانى كاهش غلظت HDL-c و افزايش سطح LDL-c سرم در كروه هاى جنسى بر حسب سن در معلمان استان

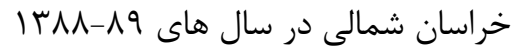

\begin{tabular}{|c|c|c|c|c|c|c|}
\hline $\begin{array}{l}\text { P-Value } \\
(\text { Chi-2) }\end{array}$ & $\begin{array}{c}\text { (\%) } 1 \text { (\%) } \\
\text { نامطلوب }\end{array}$ & $\begin{array}{c}\text { P-Value } \\
\text { (Chi-2) }\end{array}$ & $\begin{array}{c}\text { HDL-c } \\
\text { نامطلوب (\%) }\end{array}$ & ت ت تعداد & گروه سنى (سال) & جنس \\
\hline \multirow[t]{2}{*}{$\cdot 1 \cdot \cdot 1$} & $8 / / 0$ & $\cdot 199$ & $\Delta F / \Gamma$ & ITTV & كمتر از هأ سال & مذكر \\
\hline & $\Delta \Delta / 1$ & & $\Delta F / T$ & FF.r & بيشتر از ه\& سال & \\
\hline- & $\Delta G / G$ & - & $\Delta F / \Gamma$ & $\Delta V r$. & 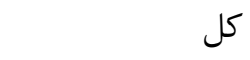 & \\
\hline \multirow[t]{2}{*}{$\cdot 1 \cdot \cdot \cdot 1$} & $V T / T$ & .194 & 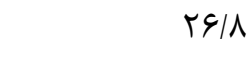 & $1 \cdot r \Delta$ & كمتر از هُ سال & مونث \\
\hline & $\Delta V / G$ & & $T V / D$ & $9 q \Delta \Lambda$ & بيشتر از ه أ سال & \\
\hline- & $4 \cdot \pi$ & - & $T V / T$ & $\Delta 91 \mu$ & كل & \\
\hline
\end{tabular}

جدول ه: ارتباط كلسترول و ترى كليسريد سرم با ميزان مصرف ميوه، سبزى، ماهى و لبنيات طى هفته در معلمان استان

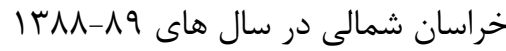

\begin{tabular}{|c|c|c|c|c|c|}
\hline \multicolumn{2}{|c|}{ وضعيت ترى كليسريد } & \multicolumn{2}{|c|}{ وضعيت كلسترول } & & \multirow[b]{2}{*}{ متغير } \\
\hline $\begin{array}{c}\text { P-Value } \\
\text { (Chi-2) }\end{array}$ & 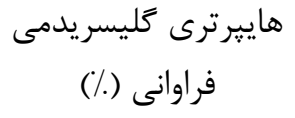 & $\begin{array}{c}\text { P-Value } \\
(\text { Chi-2) }\end{array}$ & 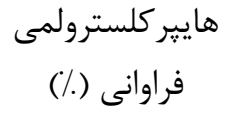 & & \\
\hline سזות. & $\begin{array}{c}r \Delta \\
r m / g\end{array}$ & $\cdot 1 \cdot \cdots 1$ & $\begin{array}{l}r q / 1 \\
r V / l\end{array}$ & ندارد & مصرف ميوه \\
\hline ./AVT & $\begin{array}{l}m F / G \\
M F / D\end{array}$ & $\cdot 1 \cdot \cdots 1$ & $\begin{array}{c}r \Delta / q \\
r \cdot\end{array}$ & 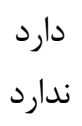 & مصرف سبزى \\
\hline$\cdot / T 10$ & $\begin{array}{l}r m / T \\
r F / \Lambda\end{array}$ & $\cdot 1 \cdot \cdot V$ & $\begin{array}{l}r \Delta / \Lambda \\
r m / \mathcal{T}\end{array}$ & 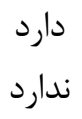 & مصرف ماهى \\
\hline$\cdot 109$. & $\begin{array}{l}M F / V \\
\mu F / T\end{array}$ & $\cdot 1 \cdot \cdot 1$ & $\begin{array}{c}r \Delta / q \\
r \cdot\end{array}$ & 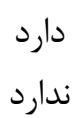 & مصرف لبنيات \\
\hline$\cdot / 419$ & $\begin{array}{l}r F / \mathcal{E} \\
r g / r\end{array}$ & $\cdot / \cdot r \Lambda$ & $\begin{array}{l}r F / q \\
r T / F\end{array}$ & ندارد & مصرف مواد سرخ \\
\hline
\end{tabular}




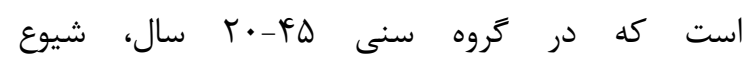
هايير كلسترولمى، هاييرترى گليسريدمى و سطح

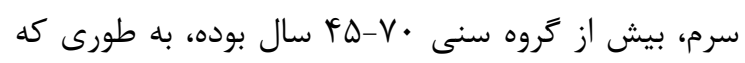

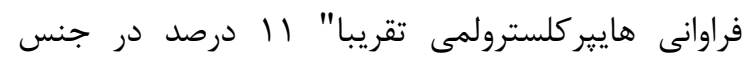
مذكر و 19 درصد در جنس مونث بيش از كروه سنرو سنى دوم

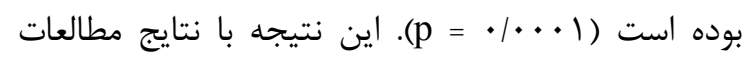

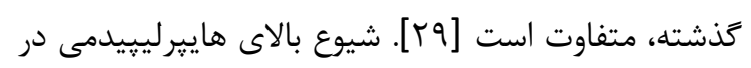
كروه سنى كمتر از هif سال، ممكن است به دليل اليل فعاليت

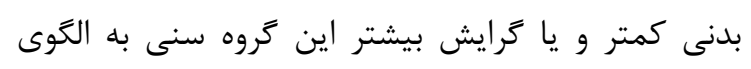

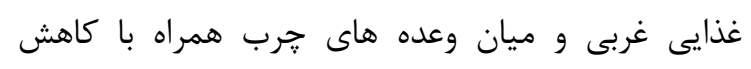

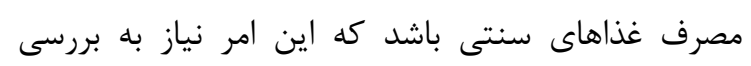

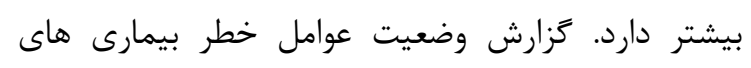

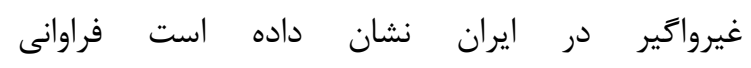

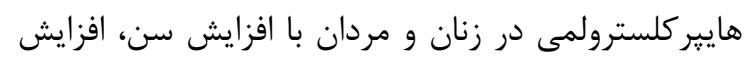

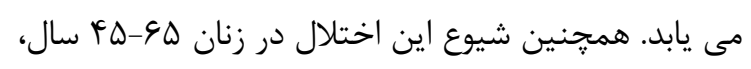

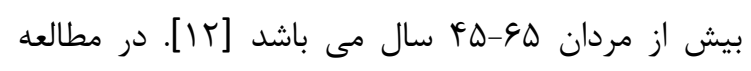

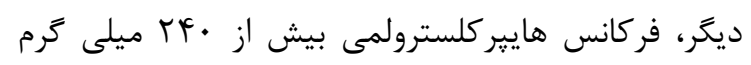

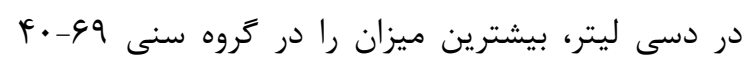

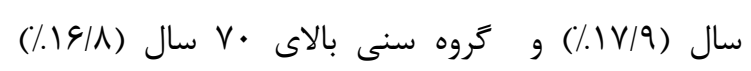

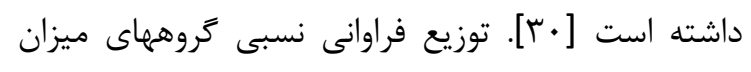

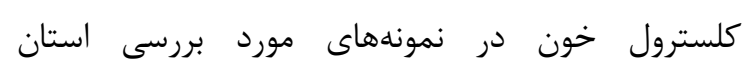

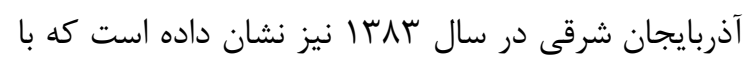

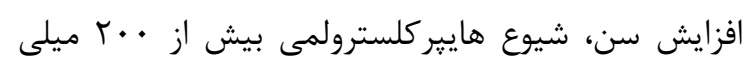

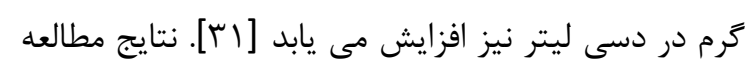

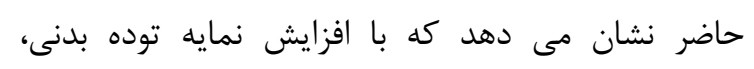

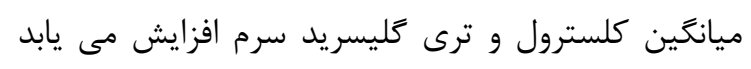

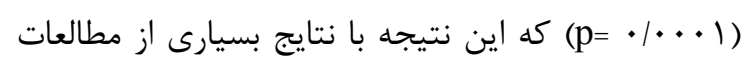

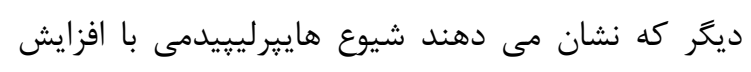

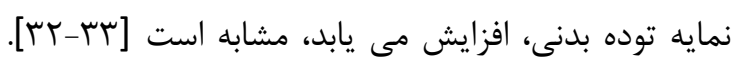

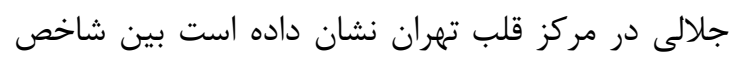
توده بدنى با ابتلا به سكته قلبى ارتباط مستقيم وجود نهان

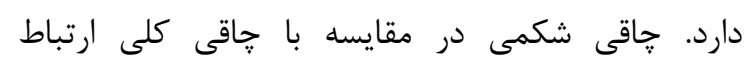

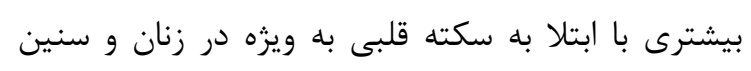

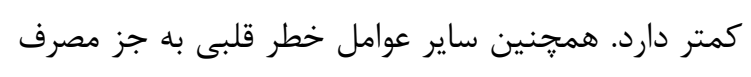

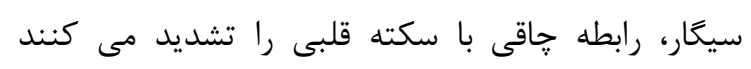

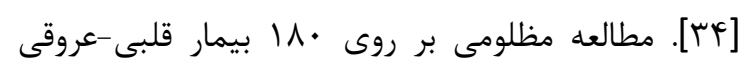

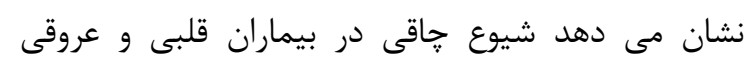

جدول شماره ه، ارتباط وضعيت كلسترول و ترى گليسريد سرم با مصرف ميوه، سبزى، ماهى و لبنيات در هفته را در

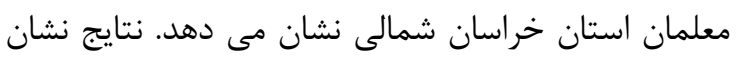
دادند در افرادى كه ميوه، سبزى و ماهى مصرف نموده اند،

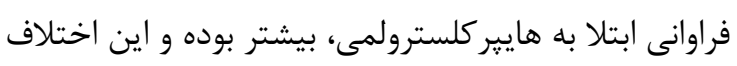

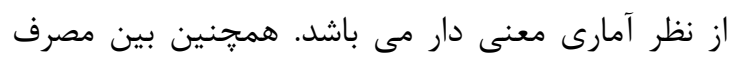

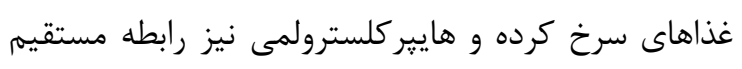

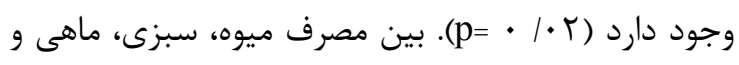
لبنيات با وضعيت ترى كليسريد سرم، ارتباطى مشاهده نَخرديد.

\section{بحث}

در مطالعه حاضر، فراوانى هايير كلسترولمى در مردان و

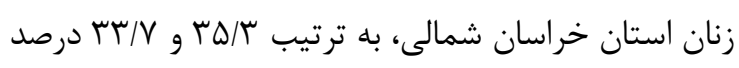

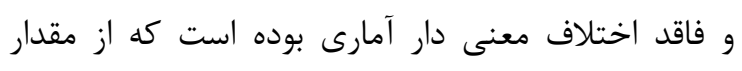
كزارش شده در بالغين ايرانى بسيار بيشتر است. به طورى

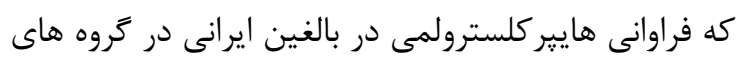

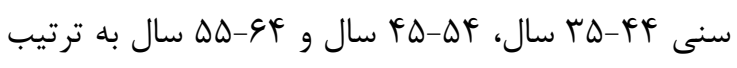

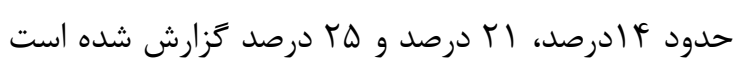

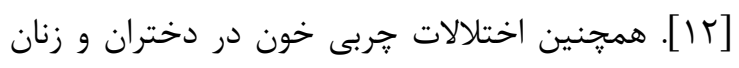

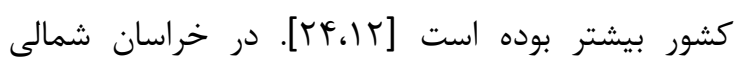

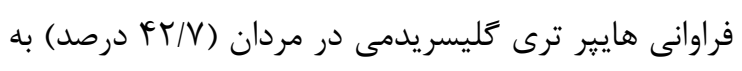

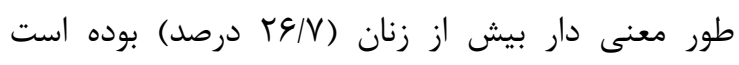

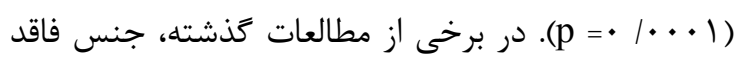

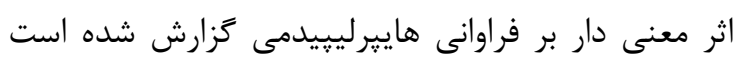

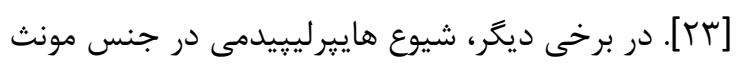

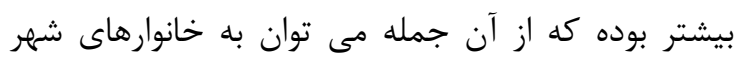
تبريز اشاره كرد كه ميزان شيوع هايير كلسترولمى در در آنها در مجموع با 1/9 درصد ززارش شده است. در مطالعه

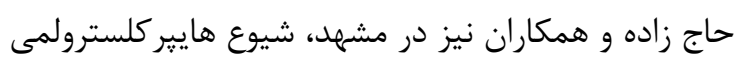

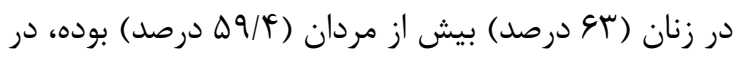

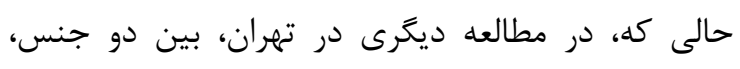

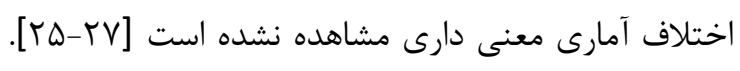

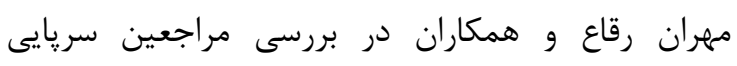
هياتيت جرب غير الكلى به بيمارستان شريعتى اصفهان،

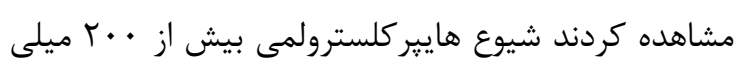

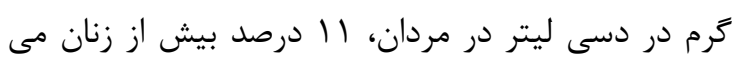

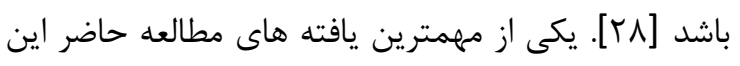




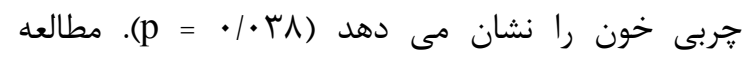

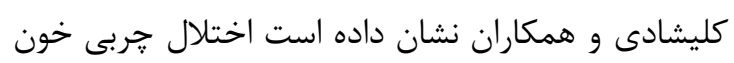
در جامعه ممكن است به طور عمده به دليل عادات

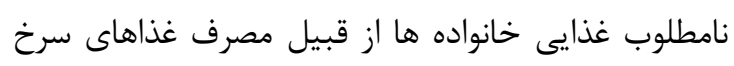

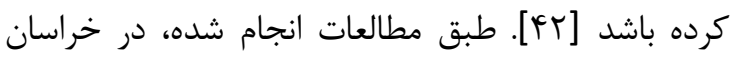

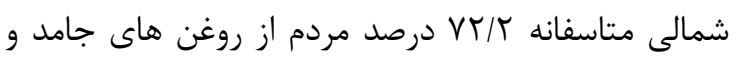

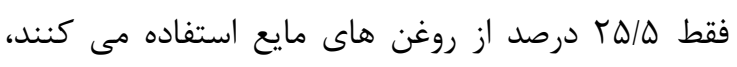

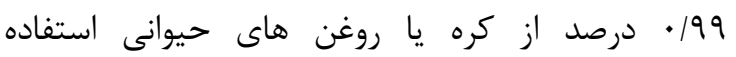

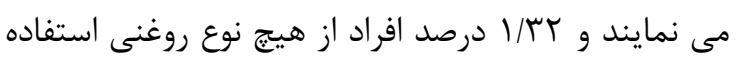

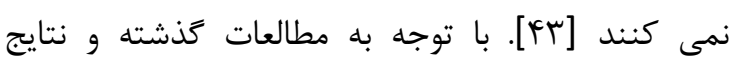

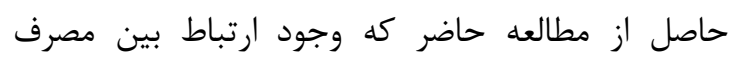

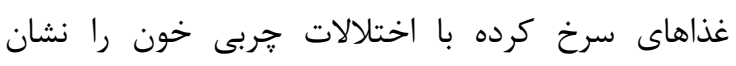

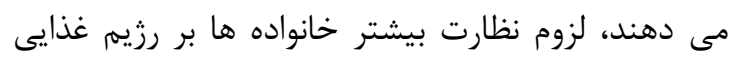

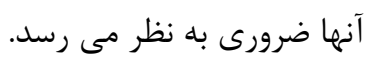

نتيجه كيرى به طور كلى، نتايج مطالعه حاضر نشان مى دهد افزايش

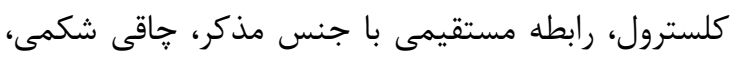

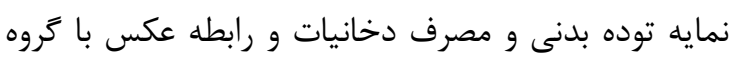

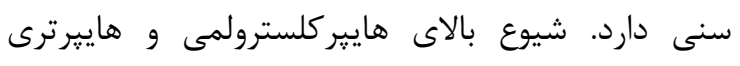

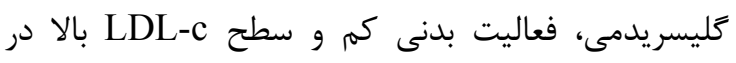

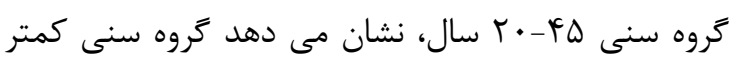

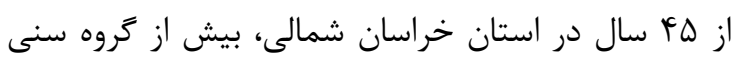

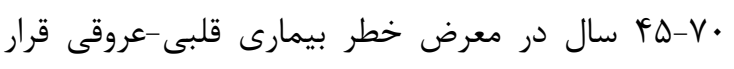

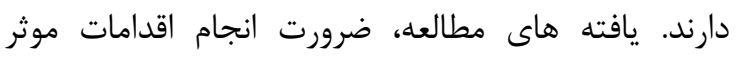

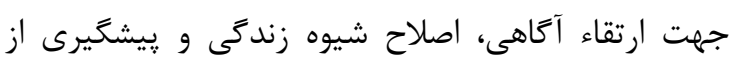

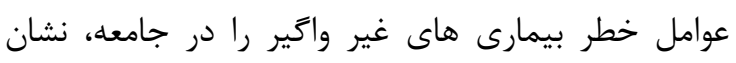

اين مقاله حاصل يزوهش هاى مشترك انجام شده توسط

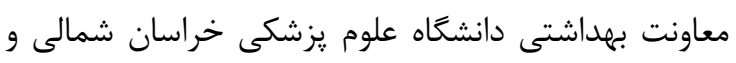
اداره كل آموزش و يرورش و معلمان استان خراسان شمالى بوده است و نويسندكان مقاله بدين وسيله از كليه

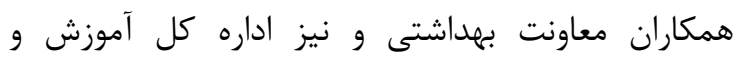

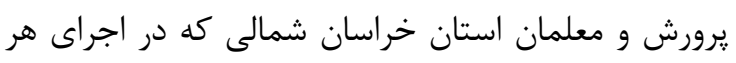
جه بهتر اين يروزه صميمانه همكارى نمودند، تشكر و و

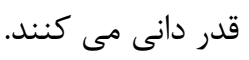

بالاست و بيشتر زنان مبتلا به اين بيمارى داراى جاقى

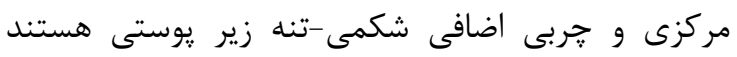

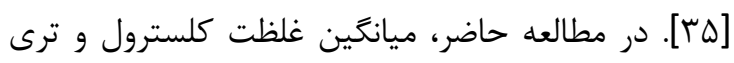

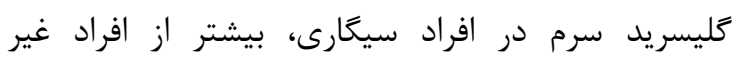

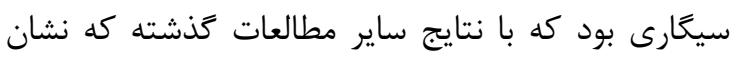

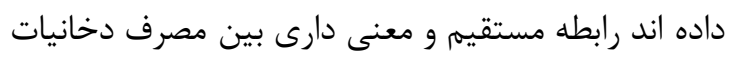

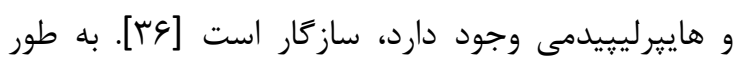
كلى، نتايج مطالعه حاضر نشان مى دهد دهد افزايش كلسترول، رابطه مستقيمى با جنس مذكر، جاقى شكمى، نمائ نمايه توده

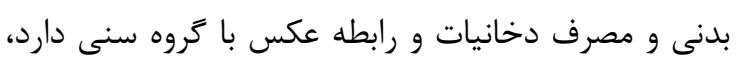
در حالى كه، افزايش ترى كليسريد، با جنس مونث ارنبان ارتباط

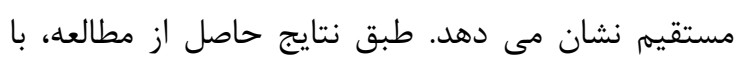

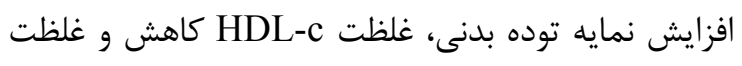
LDL-c

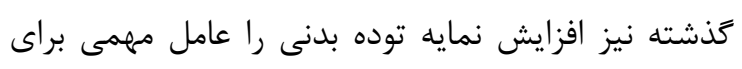

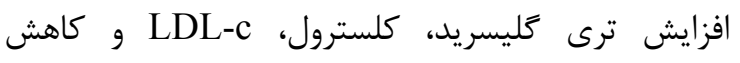
FDL-c

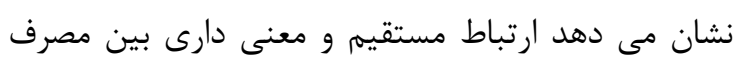

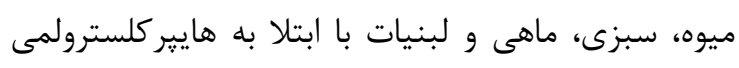

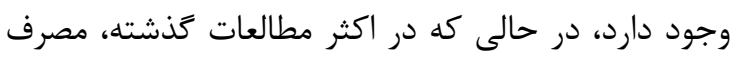

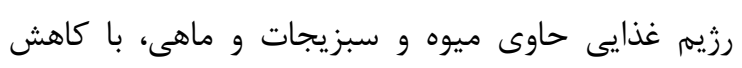

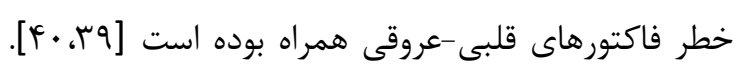

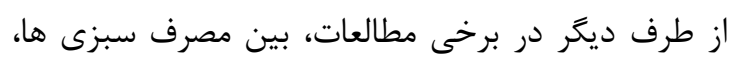

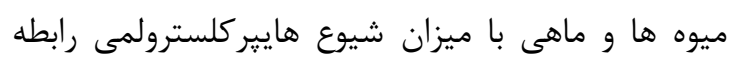

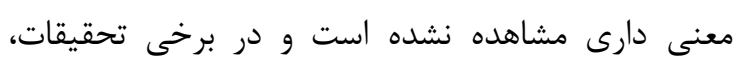

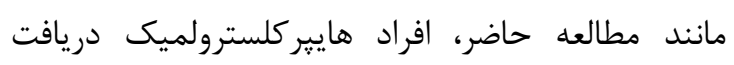
بالاترى نسبت به افراد سالم داشته اند [بس]. در توضيح اين نتيجه مى توان به مطالعه انجام شده در زاين اشاره

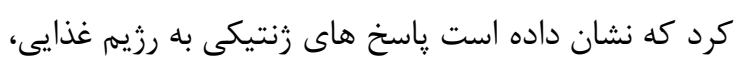

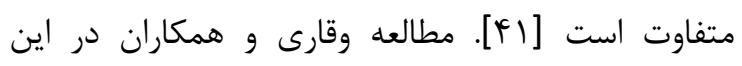

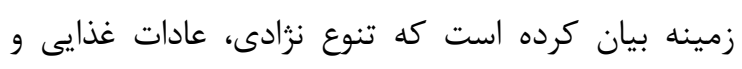

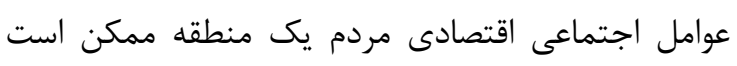

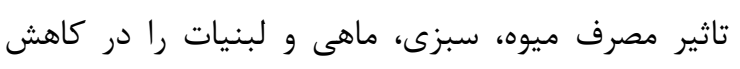

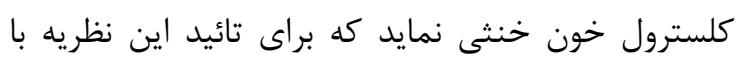

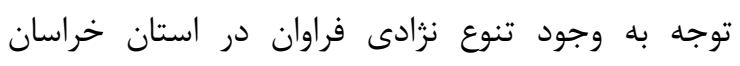

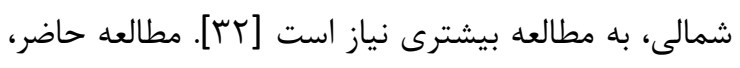
وجود ارتباط بين مصرف غذاهاى سرخ كرده با اختلالات نئل 


\section{References}

1. Maley RW, Weisgraber KH, Farese RV, Disorders of lipid metabolism. In:Andreoli TE, Williams textbook of endocrinology, 9 th edition, W. B Saunders Company 2000, 1096-8.

2. Oancă ME, Azoicăi D, Manole A, Ivan A, Contributions at clinical epidemiological peculiarities of essential arterial hypertension knowledge in a geographical area from Moldavia, Romania, Rev Med Chir Soc Med Nat Iasi 2007; 111(4):1012-6.

3. Feng Y, Zang T, Xu X. Familial aggregation of metabolic syndrome and its components in a large Chinese population, Obesity (Silver Spring) 2008; 16(1):125-9.

4. Kolovou GD, Anagnostopoulou KK, Damaskos DS, Mihas C, Mavrogeni S, Hatzigeorgiou G, "et al", Gender influence on postprandial lipemia in heterozygotes for familial hypercholesterolemia, Ann Clin Lab Sci 2007; 37(4):335-42.

5. Statistical Center of Iran. Population and Housing Census, Available from: URL: http://www.sci.org.ir (Accessed: May 7, 2006).

6. Lowering cholesterol to reduce the risk of heart disease, stroke and peripheral arterial disease, National Institute for Health and Clinical Excellence, Information about NICE clinical guideline 67, Issue date: May 2008.

7. Schaefer EJ, Hyperlipidemia and coronary artery disease, In: Becker KL, Principles and practice of endocrinology and metabolism, 2nd ed. Philadelphia: Lippincott Williams and Wilkins 1995; 137880 .

8. Citkowitz E, Hypertriglyceridemia, Emedicine from WebMD, Available from: URL: http://emedicine.medscape.com/article/126568-overview, (Accessed: Jan 5, 2010).

9. Roth GA, Fihn SD, Mokdad AH, Aekplakorn W, Hasegawae T, Limc SS, High total serum cholesterol, medication coverage and therapeutic control: an analysis of national health examination survey data from eight countries. Bull World Health Organ 2011; 89:92-101.

10. Perfil Lipídico da População Portuguesa. Fundação Portuguesa de Cardiologia. Instituto de Alimentação becel 2001.

11. Costa J, Oliveira E, David C, Borges M, Gouveia M, Carneiro AV, Prevalence of Hypercholesterolemia in Portugal and Europe: The Same Reality, Rev Port Cardiol 2003; 22 (7-8): 967-974.

12. Delavari AR, Alikhani S, Alaeddini F, The report of risk factors status of non communicable diseases in Islamic Republic of Iran, Ministry of Health and Medical Education, Department of Health, The Centers for Disease management, The risk factors care office for non communicable diseases, Press Center Sadra 2005. [In Persian]

13. Tehran Lipid and Glucose Study, Shahid Beheshti University of Medical Sciences, Research Institute for Endocrine Sciences and Metabolism, Available from: URL: www.endocrine.ac.ir , (Accessed: Sep 10, 2011).

14. Hatami ZN, Tahvildari S, Ghafarzadeh MA, Sabouri KA, Prevalence of coronary artery disease risk factors in Iran: a population based survey, BMC Cardiovasc Disord 2007; 30;7(1):32.

15. Nabipour I, Vafajou F, Mohajeri MS, Salimi-pour H, Aboutalebi SH, Analib P, Jafari M. Hyperlipidemia disorders in vascular events in Bushehr Province: A prospective study, Iranian journal of diabetes and lipid 2002; 2(1): 31-38. [Article in Persian]

16. Hadjzadeh M Al R, Neamaty H, The Prevalance of Hypercholesterolemia in Middle-Aged and Elderly Population in Mashhad and its Relation to Hypothyroidism, Medical Journal of Mashhad University of Medical Sciences 2007; 96(50):161-170. [Article in Persian]

17. Meydani M, Vitamin E modulation of cardiovascular disease, Ann N Y Acad Sci 2004; 1031: 271-9. 18.Taghavi M, The Face of Death in 18 provinces of Islamic Republic of Iran during 2001, Ministry of Health and Medical Education, Department of Health 2002: 123. [In Persian]

19. World Health Organisation: Measuring Obesity: Classification and Distribution of Anthropometric Data, Nutr UD, EUR/ICP/NUT 125, Copenhagen, WHO 1989. 
20. American Heart Association, http://www.heart.org/HEARTORG/Conditions/Cholesterol/ AboutCholesterol/What-Your-Cholesterol-Levels-Mean_UCM_305562_Article.jsp , Updated:Mon, 3 Jan 2011 8:49:00 AM.

21. Costa J, Borges M, Oliveira E, Gouveia M, Carneiro AV, Incidence and prevalence of hypercholesterolemia in Portugal: a systematic review, Part III, Rev Port Cardiol 2003; 22(6):829-36.

22. Jousilahti P, Vartiainen E, Pekkanen J, Tuomilehto J, Sundvall J, Puska P, Serum cholesterol disease risk: Observations and predictions among middle aged population in eastern Finland, Circulation 1998; 97(11): 1087-94.

23. Karimi F, Rayani M, Akbarzadeh S, Khakzad M, Tahmasebi R, Arab J, "et al", Prevalence of hyperlipidemias in adult population (=>19 years) of Bushehr port, 1999, Iranian South Medical Journal 2001; 2(3): 98-106. [Article in Persian]

24. Moayeri H, Aghighi Y, Prevalence of Hyperlipidemia in a group of obese Adolescents in Tehran, MJIRC 2006; 8(3): 30-35.

25. Feng Y, Zang T, Xu X, Familial aggregation of metabolic syndrome and its components in a large Chinese population, Obesity (Silver Spring) 2008; 16(1):125-9.

26. Hadjzadeh M Al R, Neamaty H, The Prevalance of Hypercholesterolemia in Middle-Aged and Elderly Population in Mashhad and its Relation to Hypothyroidism, Medical Journal of Mashhad University of Medical Sciences 2007; 96(50):161-170. [Article in Persian].

27. Nematipour E, Nikfallah A, Fotouhi A, Study of Lipid profile and the prevalence of its disturbances in Tehran citizens, Journal of Medical Council of Islamic Republic of Iran 2005; 4(22): 330-337. [Article in Persian]

28. Mehran Rogha, Nazila Najafi, Azadeh Azari, Mahboubeh Kaji, Zahra Pourmoghaddas, Fereshteh Rajabi, and Mina Rezaee, Non-alcoholic Steatohepatitis in a Sample of Iranian Adult Population: Age is a Risk Factor, International Journal of Preventive Medicine 2011; 2(1): 24-27.

29. Janghorbani M, Amini M, Gouya MM, Delavari A, Alikhani S, Mahdavi A, Nationwide survey of prevalence and risk factors of prehypertension and hypertension in Iranian adults, J Hypertens 2008; 26(3): 419-26.

30. WHO global strategy on diet, physical activity and health: Eastern Mediterranean regional consultation meeting report, World Health Organization 2003, 15. Cairo, 30 April - 2 May 2003.

31.Statistic \& Medical Informative office, Available from: URL:

http://ict.tbzmed.ac.ir/national\%20surveys/diseases/New\%20Folder/4_1.htm ， (Accessed: Oct 9, 2011).

32. Vaghari GH, Joshaghani HR, Hoseini SA, Sedaghat SM, Niknezhad F, Angize AH, Tazik E, Mahalouee P, The prevalency of hypercholesterolemia and some effective factors in Golestan Province, The School of Allied Medical Sciences journal, Tehran University of Medical Sciences Payavard Salamat 2009; 4(3): 10-24. [Article in Persian]

33. Williams PT, Hoffman K La I, Weight-related increases in hypertension, hypercholesterolemia and diabetes risk in normal weight male and female runners, Arterioscler Thromb Vasc Biol 2007; 27(8): 1811-9.

34. Jalali $\mathrm{F}$, Hajian $\mathrm{K}$, The relationship of myocardial infarction with waist-to-hip ratio and height. Daneshvar 2003; 11(49): 7-12. [Article in Persian]

35. Mazloum Z, Hejazi N, Ekramzadeh M, Anthropometric measurements and its relation to hypertension in cardiovascular disease patient. Jahrom medical journal 2010; 7(3):15-22.

36. Karimi F, Rayani M, Akbarzadeh S, Khakzad M, Tahmasebi R, Arab J, "et al", Prevalence of hyperlipidemias in adult population $(=>19$ years) of Bushehr port, 1999, Iranian South Medical Journal 2001; 2(3): 98-106. [Article in Persian].

37. Heimburger DC, Nutrition s interact with health and disease, In: Goldman L, Bennett JC, Cecil textbook of medicine. $21^{\text {st }}$ ed, W. B. Saunders Company 2000, 1097-8.

38. Sunyer FX, Obesity, In: Goldman L, Bennett JC, Cecil textbook of medicine. $21^{\text {st }}$ ed, W. B. Saunders Company 2000, 1155-62.

39. Balas Nakash M, Perichart Perera O, Pantoja de Anda L, Rodríguez Cano A, Ortiz Luna G, Nutritional evaluation in Mexican postmenopausal women with metabolic syndrome, Ginecol Obstet Mex. 2007; 75(9): 515-26. 
40. Grant R, Bilgin A, Zeuschner C, Guy T, Pearce R, Hokin B, Ashton J, The relative impact of a vegetable-rich diet on key markers of health in a cohort of Australian adolescents, Asia Pac J Clin Nutr 2008; 17(1): 107-15.

41. Couch Sarah C, Cross Audrey T, Kida Kaichi, Ros Emilio, Plaza Ignacio, Shea Steven, Deckelbaum Richard, Rapid westernization of children's blood cholesterol in 3 countries:evidence for nutrient-gene interactions? Am J Clin Nutr 2000; 72(suppl):1266S-74S.

42. Kelishadi R, Sarrafzadegan N, Hashemipour M, Sadri HGh, Rafiee-Tabatabaee S, Pashmi R, Ansari R, Bashardoust N, Khasi HA, Shahab M. The status of serum lipids and dietary fat in adolescents: Isfahan Healthy Heart Program - Heart Health Promotion from Childhood, Journal of Semnan University of Medical Sciences 2003; 4(3, 4): 167-176. [Article in Persian]

43. Akbari MR, Azizi SH, The report of risk factors status of non communicable diseases in North Khorasan Province 2008, North Khorasan University of Medical Sciences, Department of Health, The Fight against Disease Group 2009. [In Persian] 
Original Article

\title{
I ne prevarence of hyperlipidemia and some effective factors in teachers of North Khorasan Province
}

\author{
Majdi $M R^{1}$, Nickparast $N^{2}$, Bagherzadeh ${ }^{3}$, Puradine $M^{4}$, Sabery Karimian $M^{5 *}$,Khani $H^{6}$, Ghorbani $A^{7}$ \\ ${ }^{1}$ Mashhad University of Medical Sciences, Mashhad, Iran \\ ${ }^{2}$ Iranian Applied Research Center for Public Health and Sustainable Development (IRCPHD), North Khorasan University of \\ Medical Sciences, Bojnurd, Iran \\ ${ }^{3}$ Educational organization of North Khorasan Province, Bojnurd, Iran \\ ${ }^{4}$ Iranian Applied Research Center for Public Health and Sustainable Development (IRCPHD), North Khorasan University of \\ Medical Sciences, Bojnurd, Iran \\ ${ }^{5}$ Iranian Applied Research Center for Public Health and Sustainable Development (IRCPHD), North Khorasan University of \\ Medical Sciences, Bojnurd, Iran \\ ${ }^{6}$ Iranian Applied Research Center for Public Health and Sustainable Development (IRCPHD), North Khorasan University of \\ Medical Sciences, Bojnurd, Iran \\ ${ }^{7}$ Iranian Applied Research Center for Public Health and Sustainable Development (IRCPHD), North Khorasan University of \\ Medical Sciences, Bojnurd, Iran
}

\section{${ }^{*}$ Corresponding Author:}

Iranian Applied Research Center for Public Health and Sustainable Development (IRCPHD), North Khorasan University of Medical Sciences, Bojnurd, Iran E-mail: maryam_sabery2005@yahoo.com

\begin{abstract}
Background \& Objectives: lipids play (or have) a major role in many critical functions of body but their growing up can increase the risk of cardiovascular diseases. This study investigates the hyperlipidemia incidence and its relationship with nutritional pattern, life style and anthropometric indices in North Khorasan Province, Iran.

Materials \& Methods: it is a cross-sectional study, which was performed on the teachers of North Khorasan province since 2009 to 2010. Demographic features, nutritional patterns, life style and Anthropometric indices were measured and recorded by using of standard scales. An $8 \mathrm{~mL}$ fasting blood sample was collected after $12 \mathrm{~h}$ fasting. Blood samples were centrifuged at 3000 $g$ for 10 minutes and the serum aliquots was separated and stored at $-20{ }^{\circ} \mathrm{C}$. The GPO-PAP and GHOD-PAP methods (Zist-chimi company kits) were usedin order to determine the cholesterol and triglyceride concentration respectively. LDL-c and HDL-C concentrations were determined using Biosystem company kits.

Findings: Total of 11704 (99.9\%) volunteers among the 11713 teachers (5730 males and 5983 females, age 50.64 \pm 6.62 years), participated in this study. The mean concentration of cholesterol, triglyceride, $H D L-c$ and $L D L-c$ in men were 196.4 $\pm 42.7,164.2 \pm 96.4,46.8 \pm 1.3$ and $107.7 \pm 3.9$ and in women was $190.9 \pm 39.8, \quad 132.1 \pm 71, \quad 50 \pm 1.2$ and $110.9 \pm 3.4$ respectively. The hypercholesterolemia and hypertriglyceridemia prevalence and increased $L D L-$ c levelin the age group 20-45 yearswas significantly more than age group 45-70 years. Hypercholesterolemia was directly associated with the male gender, central obesity and BMI body mass index and smoking, and inversely with the age group. Data was shown that the serum $H D L-c$ level in females was lower than males and the serum LDL-C concentration in males was lower than females.

Conclusion: This study shows high prevalence of hypercholesterolemia, hypertriglyceridemia, serum increased $L D L-c$ level, low physical activity in the age group 20-45 years. It seems that the lower age group expose to the heart disease more than age group 45-70 years.

Keywords: Hyperlipidemia, Cardiovascular disease, Teachers
\end{abstract}

Submitted: 2012 Feb 4

Revised: 2012 Apr 9

Accepted: 2012 Jun 7 